\title{
Big brother or harbinger of best practice: Can lecture capture actually improve teaching?
}

\author{
Paul Joseph-Richard* \\ Tansy Jessop* \\ Godwin Okafor* \\ Timos Almpanis** \\ Daran Price* \\ *Southampton Solent University, ${ }^{*}$ University of Greenwich
}

\begin{abstract}
Lecture Capture (LC) is used increasingly in the UK, and has become a normal feature of higher education. Most studies on the impact of lecture capture have focused on benefits to student learning, the flipped classroom, or student non-attendance at lectures following its introduction. It is less clear how the use of lecture capture has impacted on lecturers' own academic practice. In this study, we use a mixedmethods approach to explore the impact of this intrusive yet invisible technology on the quality of teaching. We have mapped our findings to the UK Professional Standards Framework (UKPSF). In doing so, our data paints a mixed picture of lecture capture's Janus-faced reality. On the one hand, it enhances lecturer self-awareness, planning and conscious 'performance'; on the other, it crushes spontaneity, impairs interaction and breeds wariness through constant surveillance. While the Teaching Excellence Framework (TEF) rewards institutions for providing state of the art technology and lecture recording systems, our findings pose awkward questions as to whether lecture capture is making teaching more bland and instrumental, albeit neatly aligned to dimensions of the UKPSF. We provide contradictory evidence about lecture capture technology, embraced by students, yet tentatively adopted by most academics. The implications of our study are not straightforward, except to proceed with caution, valuing the benefits but ensuring that learning is not dehumanised through blind acceptance at the moment we press the record button.
\end{abstract}

Keywords: Learning technology; Lecture Capture Systems, Academic practice, UKPSF

\section{Why another study on Lecture Capture?}

Lecture capture is an increasingly normal feature of UK higher education with usage rising from 51\% of universities recording lectures in 2012 to $71 \%$ in 2016 (UCISA 2016). The umbrella term 'lecture capture' describes a range of technologies used to digitally record and distribute lectures to students (Karnad, 2013). These have become increasingly sophisticated both in speed of access and audio-visual capability, as a result of advances in technology. They have also become increasingly commonplace (Witton, 2016). At the University of Manchester alone, for example, 42,000 lectures were recorded in 2015 , constituting $80 \%$ of the total number, with $95 \%$ of students surveyed wanting more-widespread use of recording (Davies et al., 2017). Past studies have examined the impact of LC on learner-related issues such as on students' attitudes, their in-class behaviour, attendance rates, academic performance and 
learning outcomes; more recently, a small but growing number of scholars examined lecturers' attitudes towards and concerns about LC implementation and institutional challenges (see Witthaus \& Robinson, 2015, for full review). However, relatively little research has studied the possible impact of LC on staff's own academic practice. Can lecture capture technologies actually improve teaching? Understanding the influence of LC on academic practice and its resultant impact on student learning is a critical question, particularly in the context of the rapid expansion of LC's use in universities. But technological advances are not singly responsible for the march of lecture capture across the land of UK higher education. The twin forces of markets and metrics have given impetus to universities investing in state-of-the-art technology (Brown, 2013) which are seen to improve the students' learning experience, a factor alluded to in a recent evaluation of first year of the Teaching Excellence Framework (Beech 2017; Witthaus and Robinson 2015).

In spite of extrinsic drivers, there is mounting evidence that lecture capture does actually contribute to improvements in student learning, providing opportunities for review, revision and ubiquitous access to lectures. In a study of 565 students in a veterinary medical education environment, $93 \%$ of students indicated that they learned better with lecture capture (Danielson et al. 2014, p.126), while in their study of 93 students at a medium-sized modern university, Price \& Almpanis (2015) found that $72 \%$ of students agreed that LC had the potential to improve their grades. Findings about performance are contradictory though. Some large-scale studies have established a positive impact on student grades (Hove \& Corcoran, 2008; Traphagan et al., 2009; Terry et al., 2015), while others found little or no impact (Bollmeier et al., 2010; Franklin et al., 2011; Leadbeater et al., 2013; Hadgu et al., 2016); still others underline potential negative side effects (Williams et al., 2012; Johnston et al., 2013). Leadbeater et al. (2013) found the lecture recordings "do not have a significant impact on academic performance, either across the cohort or with students that use the recordings" (p. 185) and cautioned that LC might encourage surface learning among a small number of students. In contrast, Owston et al., (2011) in their study of undergraduate students $(n=439)$ concluded that LC may 'more likely' to benefit low achieving students, because of their multiple viewing of full recordings as opposed to high achieving students' limited use of LC. Many studies explore academics' fears that lecture capture impacts negatively on student attendance (Traphagan et al. 2009; Leadbeater et al. 2013; Whitley-Grassi \& Baizer 2010). Another review of lecture capture ( $n=47$ articles) found that more than half the studies in the sample specifically addressed attendance $(n=26)$, with the majority finding no negative impact, although some did show a correlation between usage and lower attendance (Pursel \& Fang 2012). Toppin (2011) highlighted the need to recognise the significant variation found among students' and teachers' perceptions about academic performance as a result of using LC.

Research on the impact of lecture capture on teaching is less extensive. In a review of the literature, Witthaus \& Robinson (2015) identify that it prompts interactive teaching approaches such as the 'flipped classroom', evidenced in various international studies (Giannakos \& Chrisochoides, 2014; Horvarth et al., 2013; Marchand et al., 2014). The flipped classroom is a practice where the lecture is recorded and delivered prior to the session which is then dedicated to interactive learning activities. Another study reports a demand for podcast/vodcast support material to be developed not to replace the lecture but to enhance the overall teaching, learning and assessment process (Folley, 2010, p. 96). This mirrors a key recommendation of the Quality Assurance Agency (QAA) which states that 'Institutions should be cautious of using technology as a replacement for face-to-face interactions, or as a substitute for developing an active 
and collaborative learning environment and community' (Kandiko \& Mawer, 2013, p. 32). The QAA study certainly intimates that lecture capture may influence academic practice in more ways than are currently understood, some of which may actually hinder student learning. One other perspective is the battleground of intellectual property (IPR) and copyright (Rios-Amaya et al. 2016). The area of IPR is beyond the scope of our study, but it does contribute to academics' reticence in using lecture capture, and potentially drives a conservative approach to teaching. Overall, research on lecture capture tends to overlook lecturers' perceptions of the educational impact of this technology.

The questions driving our study are about the impact of lecture capture on teaching, particularly with its capacity to make public the teaching act in a public online institutional space. We were curious to understand whether academics viewed lecture capture as a neutral system, leading to 'business as usual', or whether it changed the nature of the interaction between teachers and students by becoming the site of a recorded performance. Our study took into account the literature about teaching in higher education, demonstrating as it does, variations in how lecturers perceive teaching, ranging from teacher-centred performances or 'downloads' of topics and concepts on the one hand, to more student-centred and interactive engagement with knowledge, on the other (Tight, 2012; Pratt, 1992; Kember, 1997; Prosser, Trigwell \& Taylor, 1994; Korhonen \& Weil, 2015; Samuelowicz \& Bain, 1992). More specifically we have used the UK Professional Standards Framework, a benchmarking tool for higher education teachers, as the organising framework for analysing our data. We felt that the UKPSF would provide a comprehensive lens through which to understand the impact of lecture capture on teaching. The UKPSF is a nationally recognised framework (Hibbert \& Semler, 2015), which has the virtue of identifying key dimensions of teaching knowledge and practice, and identifying values which are at the heart of university teaching. We have used the UKPSF here to map the impact of lecture capture on academic practice.

\section{The research context}

Our study is set at a medium-sized modern university situated in the south of England. The university has a strong record for innovation and leadership in learning technology, with a central unit servicing some 800 academic staff. During 2015, the university learning technology team piloted lecture capture using Panopto, subsequently scaling it up across the institution. While the university has a vision for complete coverage of all sessions, like many universities, it has adopted an opt-in policy to build momentum and spread the culture of using lecture capture without engendering resistance from academics. Within a year, and supported by training, $n=121$ academics were using lecture capture routinely and this number keeps growing. Academics retain control of the recordings and manage the resources from start to uploading to the Virtual Learning Environment. The in-class recordings generally comprise audio and screen capture of presented materials, but academics have also embraced desktop recordings beyond the classroom capture for a variety of non-lecture purposes. Since September 2015 over 3000 sessions have been recorded (2,172 hours).

\section{Research methods}

In order to provide textured insights into our question about the influence of lecture capture on academic practice, we used a mixed methods sequential design - "in which methods are used to provide additional information, rather than being fully integrated 
with one another" (Muijs \& Brookman 2016, p. 200). It enabled us to be flexible and adaptable to the dynamic research context, whilst at the same time generating reliable findings which will have greater utility to HE institutions (Bryman, 2016). Specifically, we used an 'explanatory sequential design' (Bryman, 2016, p. 639) in which a survey generated initial findings. We followed up on the survey using semi-structured interviews. This design enabled us reduce the biases associated with each method and enabled us to have a more complete picture of how lecture capture influences academic practice. Prior research that used similar sequential design informed our work (Holdsworth, 2006; Laub \& Sampson, 2004; Laub \& Sampson, 1998).

During the first stage, we designed a 51 item questionnaire. We grouped the items using the categories within the UKPSF, under the five areas of activity, the six areas of core knowledge and four professional values. Each statement had options for respondents to rate them on a 5-point Likert scale, ranging from 'Strongly Disagree' to 'Strongly Agree'. We piloted the survey with five expert lecturers, who use lecture capture more frequently, "to eliminate problems of wording, length or approaches" (Krenzke, Van de Kerckhove \& Westat, 2005, p. 3259). Based on the findings of the pilot, minor refinements were made to sharpen the focus of certain questions. Then, in accordance with the good practice principles, described in Fan and Yan (2010) and Couper (2008), the questionnaire was designed as a web survey. All 121 LC trained staff were provided with a link to the web survey. In order to reduce non-response bias, small incentives were provided and two email reminders were sent. Based on the analysis of the survey findings, we then developed an interview schedule to further explore reasons and explanations for some of the findings obtained. We conducted semi-structured interviews with a purposive sample of 12 lecturers who had signalled in their questionnaire responses that they were prepared to be interviewed. Interviews were then transcribed verbatim. In the current study, we limit our analysis to the five areas of activity in the UKPSF.

\section{Data Analysis}

A total of 46 staff from across the university completed the online survey, yielding a response rate of $38 \%$, with $57 \%(n=26)$ of respondents male and $43 \%(n=20)$ female. We used SPSS 16 software to conduct quantitative analysis of the data, mainly descriptive statistics. Drawing on principles of thematic analysis within qualitative research, we coded 12 interview transcripts and categorised themes emerging from the data and in relation to the UKPSF dimensions (Joffe \& Yardley 2004; Fereday \& Eimear, 2006; Braun \& Clarke, 2006). Two researchers independently read each transcript and derived themes in an iterative process, in line with the pre-determined analytic framework (UKPSF), before comparing their results for consistency and resolving discrepancies through discussion. Coding was organised in relation to the UKPSF framework but the pre-determined framework was not used rigidly in that the researchers were open to new themes emerging from the data.

\section{Findings}

The findings draw on the questionnaire data and use qualitative data to confirm and contest the numeric data. We have organised the findings under the five UKPSF Areas of Activity but have resisted the temptation to construct a validating discourse, either for lecture capture or for the UKPSF. Our research question about whether lecture capture influences academic practice is at the forefront of the study, and the lens for exploring academic practice is the UKPSF's five areas of activity. These are: 
A1: Design and plan learning activities and/or programmes of study

A2: Teach and/or support learning

A3: Assess and give feedback to learners

A4: Develop effective learning environments and approaches to student support and guidance

A5: Engage in continuing professional development in subjects/disciplines and their pedagogy, incorporating research, scholarship and the evaluation of professional practices.

\section{Impact on planning and designing (A1): "You'd better get your facts straight"}

In response to the survey, a small majority of lecturers believed that LC had not impacted the design of lectures (59\%), or their planning of lectures $(60 \%)$. Interview data provided a more nuanced picture of the impact of LC on designing and planning sessions, challenging a 'business as usual' view with its implication of LC being neutral rather than shaping or disrupting practice. Some lecturers described LC as providing impetus for more thoughtful planning given that the content of lectures is recorded and public; others described it in slightly more worrying tones, as crushing spontaneity and prompting a more studied interaction with students, closing down the casual, informal, relationship-building elements of teaching. The comments below evidence both of these perceptions:

You immediately become more professional and thoughtful about the content and how it'll come across because it is recorded (R2).

You've got to think very carefully about what you're going to say if this is going to be used in evidence of what you said. So first of all you can't have errors, you might casually throw a remark in, a line you invent, which you wouldn't wish people to see in the recording. Second you better get your facts straight, because you could be on record as talking rubbish. It impacts on the planning... my time planning has increased by $50 \%$... (R6).

Both the technology and recording of lectures prompted innovation among some lecturers. This ranged from the possibility of using all the functions of LC to personalising learning to elements of flipping the classroom:

When I found out what LC looks like that's when I started to add additional things...knowing the different functions now I will start to incorporate things (R7).

Initially I thought of it as a way of recording for students who are missing but I realised that this was a good way of adding extra value and engagement. It can be used very interactively. Currently l've been using it with PPT and my voice but next year l'd like to get a camera so it's more personal (R8).

I decided I couldn't do everything in three hours so each week leading up to the session I did a LC video. I've broken up a busy three hour session and now they can do independent learning and choose what they're interested in. I may do a $L C$ to cover complicated topics (R8).

The view that LC does not change design or planning, reflected in the survey results, is inseparable from entrenched teaching philosophies and practices, illustrating imperturbable continuities with previous practice among certain lecturers: 
I don't think it has had a massive effect on how I do things for $x$... which is very much a "I speak, they listen" kind of subject. It's difficult to make it interactive... the vast majority of the delivery is from power points and the students listening (R10).

Overall, $53 \%$ of respondents used LC to record classroom-only sessions; $9 \%$ used it outside the classroom, and $33 \%$ used a mixture of both approaches. Although $46 \%$ of the sample agreed that LC has facilitated the use of additional learning resources, it appears to have had limited and quite mixed effects on designing and planning learning sessions.

\section{Impact on teaching and supporting learning (A2): Silencing spontaneity yet increasing awareness}

Survey responses showed that more lecturers felt that LC had positively impacted their practice than not (55\%). A narrow majority described LC as giving impetus to using more examples and content materials (56\% and $54 \%$ respectively); while most indicated that LC had not limited their use of humour (80\%). Interviews provided contrasting data about the impact of LC on the use of humour in interactions with students. The following comments suggest that LC curtails these informal exchanges with students:

I tried not to make too many jokes because they might not come across as well as they do in person (R1).

I use humour a lot which works with the students... to an extent you are more careful about what you say (R5).

Once you have said you're recording, the whole room falls silent and very few people talk (R6).

Almost half of the lecturers in the survey described LC as leading them to modify their practice (48\%) and positively influenced their use of active learning techniques (48\%). The survey did not indicate in which direction modifications were made, nor whether LC encouraged more or less interactive approaches to learning and teaching. The interview data sheds some light on the kinds of modifications prompted by LC. Lecturers described changes in tone and their teaching persona, as a result of greater self-awareness:

I tried to talk slower. I don't know if I succeeded because I never watched them. I tried to be engaging. I tried to look at the camera a lot (R1).

I was more silent in discussions than otherwise as I realised the students listening back wouldn't want to hear my voice and as it was for an assessment I wanted to be quiet (R2).

The first time I listened back I was horrified. I couldn't believe it... I'm not saying how bad I was because I think I'm quite reasonable. But I came across in certain places as a bit whiny with the students. You know, I was moaning at them. It sounds ok when you are doing it at the time but when you listen back... oh I can't do that. So it has absolutely influenced the way I teach. It has a BIG impact on the way I teach. No two words about it! (R9).

In both survey and interview data, lecturers described a key benefit of LC as its impact on their ability to accommodate diverse needs (80\%), increasing their awareness of inclusivity (69\%) and their knowledge of individual needs (48\%). This increased awareness was a catalyst for more learner-centred teaching, and an 
impetus for using LC creatively. Lecturers' comments evidenced their deeper understanding of student needs:

It's not impacted so much on the way I teach but on the way I support learning, for example, some students were struggling with some calculations last week, so I created an LC video for a step-by-step method of what to do and I uploaded it online (R7).

Sometimes you see a student watching the same thing so next time you see them you can ask them if they are struggling (R3)

I naturally deliver things quite fast anyway so the benefit of LC for me if I went too fast is that students could watch it again at their own speed and that came back in my feedback (R7).

\section{Impact on assessment and feedback (A3): Options to press pause and repeat}

The data shows that LC impacts assessment and feedback in mainly positive directions for student learning, but that the full functionality of LC is new territory to most lecturers. Slightly more than a third of lecturers described improvements in giving feedback to students through LC (39\%), while $56 \%$ felt that LC positively influenced assessment and feedback more generally. Lecturers' comments clustered around three themes. First, LC provided students with access to support in preparing for assessments:

When they are working on revision material, and they realise they have not understood, the videos are students first port of call (R10)

Before exams my LC get a lot of views (R4)

I've used it for video assessment briefs. Traditionally it is written down and some people find it hard to keep up with this or understand it... I get a lot of positive feedback about it in particular the video assessment briefs. Students find those really useful ( $R 7)$.

Second, LC enabled lecturers to give much more accurate and lively feedback to students, especially for assessment tasks such as presentations, as demonstrated here:

LC was a huge part of the assessment for this subject as they had to hand in a facilitated discussion. It was really useful for me to listen back (R2).

I've recorded student presentations so it means I give better feedback attending to the details (R5).

For one lecture, the unit leader attached the presentation video to their feedback so the feedback came more alive because they could see themselves. They clicked on their feedback in text and above there was a video (R8).

It also offered the added bonus of more robust quality assurance, with the facility to transfer oral assessments to external examiners:

l've used it for student presentations to record them and found it easier to give to the external examiners this way (R7).

Third, LC holds students more accountable in group tasks where the process is recorded, as this comment evidences: 
They're much more conscious that they need to participate more... it is easy to work out whose voice is who. They make more of an effort now that they are being recorded ( $R 2)$.

However, there are barriers to using LC for assessment and feedback, including large class sizes, but lecturers described finding inventive ways to overcome these barriers:

l'd like give students feedback by LC but it's not practical to find a quiet space to record feedback for 200 presentations or reports. What I have done is use it for generic feedback if there's a certain issue which keeps being raised (R7).

A significant barrier lecturers mentioned is not knowing how it might be used: 'I don't know how you would use it as a feedback tool' (R9).

\section{Impact on learning environment \& student support (A4): A safety net for students and staff}

Interview data spoke loudly about LC providing a powerful safety net both for students and for academic staff. For students, LC enabled students who are struggling, unable to attend or new to UK higher education to replay lectures at any time and in any place, and as often as needed. For lecturers the safety net of LC was its capacity to reduce workload, particularly with large classes. On two related items in the survey, lecturers attested to the way in which LC has changed the way that they provide student support and guidance, in a largely positive direction (54\% and $37 \%$ respectively). LC makes tutors available to their students for more of the time, and develops student autonomy:

Lecture Capture expands the classroom... the tutor is there outside of university time (R1).

If they ask for a private lesson, you can tell them to view the LC, giving them control over their own studies (R3).

Significantly, LC provides an inclusive learning experience for all students, with a few notable exceptions where the technology falls short of being inclusive:

They know they have got a safety net with lecture capture. I talk quickly. I don't go slower because I know that l've got lecture capture to back me up for the students who have special requirements... two students with severe dyslexia... I've got the rest of the class to think about because they shouldn't be impacted because of these students. That's why lecture capture is fantastic. It means that the students who have difficulties know that they can go and watch it anytime at their own pace and it makes me feel a lot more comfortable in the way I deliver my lessons knowing full well I'm not leaving anyone behind (R9).

We have a deaf student who is excluded by LC. It makes him feel like an outsider because even if I filmed it he couldn't lip read it from that distance. There should be a way to transcribe it with subtitles (R5).

Paradoxically, LC appears to enhance student engagement with the content of lectures:

I've seen more engagement with students watching the lecture online. There's more support and guidance. But there's a slightly selfish reason in doing that 
with 196 students asking the same question it gets frustrating and repetitive so now I can see I have put guidance online (R5).

I think the students are a bit more engaged than they have been previously (R7).

One of the biggest benefits for academics is that LC provides a workload safety net for them. $22 \%$ of the respondents in the questionnaire said that LC had reduced students' expectations of after-lecture and one-to-one support. The comments below evidence its efficiency and effectiveness as a means of support for students:

Emails are not great so you can make a short video, so students have a safety net (R3).

We still get a lot of students knocking on the door so LC helps offload your workload (R4).

It was the perfect storm in terms of how much work they were doing and they had one person. And they stay in the evenings, they work on the weekends, and even though I answer their email, I am just one person. I couldn't manage without $L C$ - simple as that (R9)

\section{Impact on Continuing Professional Development (A5): Knowing your students; knowing yourself}

Academics were fairly unequivocal about LCs impact on their professional development, with $80 \%$ claiming that it had contributed to their professional development. The two main areas of development discussed in interviews were about the deeper sense of knowing afforded by LC: learner analytics from LC provided rich insights into student learning enabling them to know their students better, and the recordings enabled lecturers to reflect on their own teaching practice, enabling them to know themselves as teachers better. This aligned with responses to survey items which asked whether LC had encouraged them to reflect on, and evaluate their practices, which returned agreement rates of $85 \%$ and $80 \%$ respectively. Comments showed shifts in teacher conceptions of teaching as 'performance' to seeing sessions from a student perspective, as evidenced here:

It does motivate you to think about your students watching it so you change your style (R4).

I can go back to the statistics on each video and see who is watching it and also which bits of it they are watching. So it informs my teaching. If there are a lot of students then it is material they haven't got or I haven't taught it particularly well or it's something worth revisiting (R10).

I'm looking at the activity reports a lot more to see who's accessed it. I'm now evaluating what's worth putting on the VLE and what's not (R5).

Lecturers described the impact of LC in relation to greater self-awareness, almost akin to being observed by a peer, but not quite:

It's a great way for me to assess my teaching. Am I quiet when I turn away? Am I talking too fast? It allows you to do peer observation on yourself (R8)

One of my objectives was to review my teaching using LC which I did. I don't think it replaces peer observation as there is a huge benefit to having someone else in the classroom where they can actually see you and the way you are working but as a way of reflecting on your own work, then absolutely! [it has changed my practice] (R9) 
Others described the time-saving impact of LC enabling them to develop in other ways as a professional, and the new learning involved in using the technology itself as a form of continuing professional development:

For me the biggest impact is effective working time for me (R5).

Using it in your teaching alone is enough to have impact... it's about opening new horizons. You've learnt a new technology (R1).

\section{Discussion}

The springboard for our research was our intuition that recording a lecture changes how a lecturer feels and/or performs during that lecture, an intuition confirmed by previous studies (Bond \& Grussendorf, 2013; Horvath et al. 2013). Our study has explored the impact of lecture capture on academic practice, using the dimensions of the UK Professional Standards Framework, a widely agreed benchmark which articulates the core activities of lecturering in higher education. We have painted a rich picture of academics' experience using both survey and in-depth interview data. Our findings demonstrate three salient consequences of LC for practising academics. First, lecture capture has heightened lecturers' self-reflection and awareness, enabling them to see their own teaching better, from a student vantage point. Second, it has subdued the informal discourse of the pedagogic relationship by introducing surveillance effects, including wariness about taking risks and being caught on camera, while at the same time prompting more evidence-based use of resources in teaching. Third, it has increased the potential for heightened support to students while using less resource.

Reflective practice is one of the first principles of good teaching (Schon 1987; Grace et al. 2006). In heightening self-reflection, lecture capture has prompted a shift among some of our sample from being teaching-focused to more learning-oriented. Lecturers describe their practice as being transformed by hearing and seeing their 'delivery' from a student perspective, prompting some to chunk up their teaching into bite-sized videos, or to cover complicated topics on LC, or to change the pace and tone of their lectures. More significantly, some $45 \%$ of lecturers in the survey sample described LC as a catalyst for using active-learning techniques, such as the 'flipped classroom'. This fully accords with the literature about LC (Giannakos \& Chrisochoides, 2014; Horvarth et al., 2013; Marchand et al., 2014). Interestingly, LC has prompted lecturers to investigate learner analytics associated with recordings, enabling them to adapt their teaching and use of resources. Interventions as a result of examining analytics include creating step-by-step videos for complex topics, revisiting topics and concepts with which students seem to be struggling, and adapting resources on the virtual learning environment in line with student usage.

One of the more striking consequences of lecturers' increased self-reflection and awareness of students is that LC seems to encourage lecturers to be more inclusive. Lecturers use the language of a 'safety net' to describe the inclusive effects of LC, particularly its capacity to support the learning of those with learning differences. LC's ubiquitous availability and limitless replay facilities provide an extra layer of support for students who have particular needs, while sustaining the pace and level of challenge in the teaching of complex material for students without these needs. All students benefit from LC, which is the true meaning of inclusivity.

The second effect of LC for academic practice is the 'caught on camera' effect, which provokes a raft of mixed behaviours. The most striking initial effect of LC is that it appears to close down informal discussions, humour, and risk-taking, which are at the heart of the human and relational nature of teaching (Van Manen, 1991). Lecturers describe being cautious and wary in planning and executing their classes, where one 
describes deliberately remaining silent in group discussions, and others eschew humour in case it is misconstrued. Related studies have found similar effects such as LC's inability to accommodate some different lecturing styles (Chang, 2007), diminished learning experiences for students (Gosper et al., 2011), staff's discomfort towards recording their own voices, fear of committing mistakes, and fear of materials being misused, termed as 'you tube fear' (Bond \& Grussendorf, 2013). These are powerful negative effects of LC, which are likely to diminish the relational and affective nature of teaching, and force a transactional, rational, and cerebral approach to teaching. There are also positive effects though. Lecturers describe strengthening the evidence-base of their classes, and using more contemporary and robust sources as a result of being 'caught on camera'. Arguably, LC may indirectly encourage lecturers to be more research-led in their teaching by making them more sensitive to the possible copyright issues, intellectual property rights and by forcing them to be evidence-based (Healey, Jenkins \& Zetter, 2007). Hence, a thoughtful implementation and a 'purposeful use' (Witton, 2016) of LC that facilitate more natural and humane learning and teaching needs to be encouraged.

A few respondents commented on the performance management potential of LC. Our study adds to the list of concerns that LC may be used covertly for performance management. Providing appropriate assurances and clear guidance to academic staff might enable institutions to get staff buy-in with relative ease. In addition, as UK universities are still developing their copyright and intellectual rights policies with regards to lecture recording (Rios-Amaya, Secker and Morrison, 2016; Elmes, 2016), clarifying issues such as whether or not lecturers give consent to public use of lectures, who owns the resulting outputs, who has access to them and how those outputs are managed, controlled and used, and what lecturers need to know when using third party content in lectures might promote enthusiastic and fearless adoption of this technology.

The third compelling finding in our study is that lecture capture alleviates workload burdens for academics while simultaneously increasing the effectiveness of support for students. More than a fifth of academics described LC as reducing the burden of student emails and one-to-one support, and a number described proactive and innovative strategies to provide support to students such as lecture captured guidance to students about assessment tasks. Implicit in LC support for students is its wide and fair distribution to all students, unlike email responses and one-to-one support. Lecturers were not excluding the need for one-to-one support in general, or suggesting that LC was a complete replacement for face to face support, but there was an overwhelming sense from the data that LC had provided more expansive opportunities for students to engage with their lecturers and the discipline area. One unexpected benefit of LC's capacity to support students is that it prompts greater student autonomy and independence, encouraging students to take more ownership over their learning and be less inclined to view the lecturer as the font of all knowledge. In a small way, it may contribute to their intellectual development as independent learners (Perry 1981; Baxter Magolda, 2004).

The main limitation of our study is that it is a single institution study undertaken with a relatively small sample of academics through a survey $(n=46)$ and in-depth interviews $(n=12)$. What the study lacks in size and generalisability, it compensates for in the robustness of its methods, their triangulation, and the novel use of the UKPSF as a framing device. However, given its limitations, our findings, while shedding light on the impact of LC on academic practice, should be treated with caution. A further limitation is that those who adopted LC at our institution, those who completed the questionnaire, and those who have been interviewed, were more likely to be enthusiastic about 
Lecture Capture, certainly at the outset. There may therefore have been a slight positive bias towards the LC's virtues. This is one reason why we have used more of a qualitative lens for our study, as this revealed much more of the warp and weft of their experiences with LC than survey responses. In addition, each of the dimensions of the UKPSF used here merits its own study to explore, for example, the impact of LC on curriculum design, assessment and feedback, learning environments or on senior management's openness to adopt similar technologies (Evans \& Morris, 2016) which support students' learning. Further research might widen the scope to other university contexts, or investigate the impacts described here from different perspectives, for example, students' or learning technologists' perspectives. There is also a rich vein to be explored in understanding what a technological interface like lecture capture does to the pedagogic relationship.

\section{Conclusion}

Our study has provided some clarity in answer to the question we pose in the title of our article: "can lecture capture actually improve teaching?" Like the proverbial curate's egg, our findings demonstrate that lecture capture is good in part. On the one hand, it prompts academics to reflect on their practice more intentionally, to step into their students' shoes, and to investigate learner analytics so that they can understand how their students are getting on, and support those who are struggling. For some lecturers, this is incentive enough to change their practice, to develop new resources and provide route maps through complex intellectual territory. The spotlight of lecture capture forces others to enliven their classes with evidence and new knowledge from the latest research findings. These exciting developments happen partly because the innovative use of lecture capture frees up time for lecturers, who no longer have to respond to quite as many student emails asking for clarification about assessment briefs, and who are pounced on less frequently by students lurking outside lecture theatres to clarify arguments made in the lecture.

Contrastingly, lecture capture seems to breed a studied self-consciousness among some lecturers, which detracts from the rich, funny, and surprising heartbeat of the student-teacher relationship. For some, this manifests itself in wariness, in stilted teaching encounters, and in a silenced discourse, where humour and spontaneity are seen as dangerous interlopers, likely to be caught on camera. The surveillance side of lecture capture, not only the shadow side of performance management, is an unexpected downside of lecture capture underlined by findings here, and worthy of further exploration.

Lecture capture (and/or its future iterations), is here to stay. The imprint of lecture capture is already inscribed on the fabric of higher education, and demands for its use are high from fee-paying students. Our study has provided granular evidence and a different perspective on the impact of LC, by investigating the way it informs teaching and supports learning in higher education. In the main, our findings support the view that LC has the potential to transform aspects of lecturers' practice, from curriculum design to continuing professional development. However, the 'big brother' features of lecture capture signal a warning about its impact on the informal, spontaneous threads of humane conversations that make up the more intangible and often most meaningful aspects of the student-teacher relationship.

\section{References}

Baxter Magolda, M. B. (2004) Making Their Own Way: Narratives for Transforming Higher Education to Promote Self-development (Sterling, VA, Stylus Publishing) 
Beech, D. 2017. Going for Gold: Lessons from the TEF provider submissions. HEPI. http://www.hepi.ac.uk (accessed 12 January 2018)

Braun, V. \& Clarke, V. (2006) Using Thematic Analysis in Psychology. Qualitative Research in Psychology, 3(2) 77-101

Bollmeier, S. G., Wenger, P. J., \& Forinash, A. B. (2010) Impact of Online Lecturecapture on Student Outcomes in a Therapeutics Course. American Journal of Pharmaceutical Education, 74(7), 127

Bond, S. \& Grussendorf, S. (2013) Staff Attitudes to Lecture Capture, (London: The London School of Economics and Political Science)

Bryman, A. (2016) Social Research Methods (Oxford: Oxford University Press).

Chang, S. (2007) Academic Perceptions of the use of Lectopia: A University of Melbourne Example, ICT: Providing choices for learners and learning, Proceedings. ASCILITE Singapore 2007, 135-144.

Couper, M. P. (2008) Designing Effective Web Surveys, (New York: Cambridge University Press)

Danielson, J., Preast, V., Bender, H. \& Hassall, L. (2014) Is the Effectiveness of Lecture Capture Related to Teaching Approach or Content Type? Computers \& Education, 72, 121-131

Davies, S., Mullan, J. Feldman, P. (2017) Rebooting learning for the digital age: What next for technology enhanced higher education? Higher Education Policy Institute (HEPI) Report Number 93. http://www.hepi.ac.uk (accessed 16 January 2018)

Elmes, J. (2016) Universities 'uncertain' about lecture-capture copyright. Times Higher Education Supplement. 8 December 2016.

https://www.timeshighereducation.com (accessed 16 January 2018)

Evans, L. \& Morris, N. (2016) Leading Technology-Enhanced Learning in Higher Education: Research and Development Series Report. (London: Leadership Foundation for Higher Education).

Fan, W. \& Yan, Z. (2010) Factors Affecting Response Rates of the Web Survey: A Systematic Review. Computers in Human Behaviour, 26(2), 132-139

Fereday, J. \& Eimear, M. (2006) Demonstrating Rigor using Thematic Analysis: A Hybrid Approach of Inductive and Deductive Coding and Theme Development. International Journal of Qualitative Methods, 5(1), 80-92

Folley, D. (2010) The Lecture is Dead Long Live the e-Lecture. The Electronic Journal of e-Learning, 8(2), 93-100

Franklin, D. S. Gibson, J. W., Samuel, J. C., Teeter W. A. \& Clarkson, C.W. (2011) Use of Lecture Recordings in Medical Education. Medical Science Educator, 21(1), 2128

Giannakos, M. N. \& Chrisochoides, N. (2014) Challenges and Perspectives in an Undergraduate Flipped Classroom Experience: Looking through the Lens of Learning Analytics. In 2014 IEEE Frontiers in Education Conference (FIE) Proceedings. Madrid: IEEE, pp. 1-5.

Gosper, M., McNeill, M., Woo, K., Phillips, R., Preston, G. \& Green, D. (2011) WebBased Lecture Technologies and Learning and Teaching: A Study of Change in 
Four Australian Universities. Journal of Asynchronous Learning Networks, 15(4), 84-95

Grace, S., Pilkington, R., Rush, L., Tomkinson, B., Willis, I., Evans, E., Moon, J. \& Wareham, T. (2006) The Role and Effectiveness of Reflective Practices in Programmes for New Academic Staff: a Grounded Practitioner Review of the Research Literature." Available online at: https://www.heacademy.ac.uk (accessed 11 June 2017)

Hadgu, R.M., Huynh, S. \& Gopalan, C. (2016) The Use of Lecture Capture and Student Performance in Physiology. Journal of Curriculum and Teaching, 5(1), 11

Healey, M. Jenkins, A. \& Zetter, R. (2007) Linking Teaching and Research in Disciplines and Departments. (York: Higher Education Academy)

Hibbert, P. \& Semler, M. (2015) Faculty development in teaching and learning: the UK framework and current debates. Innovations in Education and Teaching International, 53 (6), 581-591.

Hove, M. C. \& Corcoran, K. J. (2008) If you Post it will They Come? Lecture Availability in Introductory Psychology. Teaching of Psychology, 35(2), 91-95

Holdsworth, C. (2006) Don't You Think You're Missing Out, Living at Home? Student Experiences and Residential Transitions. The Sociological review, 54(3), 495519

Horvath, Z., O'Donnell, J.A., Johnson, L.A., Karimbux, N.Y., Shuler, C.F. \& Spallek, H. (2013) Use of Lecture Recordings in Dental Education: Assessment of Status quo and Recommendations. Journal of dental education, 77(11), 1431-1442

Joffe, H. \& Yardley, L. (2004) Content and Thematic Analysis. In: D. F. Marks and L. Yardley (Eds) Research Methods for Clinical and Health Psychology. 56-68. (London: Sage).

Johnston, A. N. B., Massa, H. \& Burne, T. H. J. (2013) Digital Lecture Recording: A Cautionary Tale. Nurse Education in Practice, 13(1), 40-4

Kandiko, C. B. \& Mawer, M. (2013) Student Expectations and Perceptions of Higher Education (London: King's Learning Institute).

Karnad, A. (2013) Student use of Recorded Lectures: A Report Reviewing Recent Research into the use of Lecture Capture Technology in Higher Education, and its Impact on Teaching Methods and Attendance (London: London School of Economics).

Kember, D. (1997) A Reconceptualisation of the Research into University Academics' Conceptions of Teaching. Learning and instruction, 7(3), 255-275.

Korhonen, V. \& Weil, M. (2015) The Internationalisation of Higher Education: Perspectives on Self-conceptions in Teaching. Journal of Research in International Education, 14(3), 198-212.

Krenzke, T., Van de Kerckhove, W. \& Westat, L. M. (2005) Identifying and Reducing Nonresponse Bias throughout the Survey Process. American Statistical Association Section on Survey Research Methods Proceedings. 3258

Laub, J. H. \& Sampson, R. J. (2004) Strategies for Bridging the Quantitative and Qualitative Divide: Studying Crime over the Life Course. Research in Human Development, 1(1), 81-99 
Laub, J. H. \& Sampson, R. J. (1998) Integrating Quantitative and Qualitative data, in: Z. Giele \& Elder Jr. G. H. (Eds) Methods of Life Course Research: Qualitative and Quantitative Approaches. (London: Sage). 213-230

Leadbeater, W., Shuttleworth, T., Couperthwaite, J. \& Nightingale, K. P. (2013) Evaluating the Use and Impact of Lecture Recording in Undergraduates: Evidence for Distinct Approaches by Different Groups of Students. Computers \& Education, 61, 185-192.

Marchand, J.-P., Pearson, M. L. \& Albon, S. P. (2014) Student and Faculty Member Perspectives on Lecture Capture in Pharmacy Education. American Journal of Pharmaceutical Education, 78(4), p.74

Muijs, R. D., \& Brookman, A. (2016). Quantitative methods. In C. Chapman, D. Muijs, D. Reynolds, P. Sammons, \& C. Teddlie (Eds.), Routledge International Handbook of Educational Effectiveness and Improvement Research. (Abingdon, GB: Routledge) 173-201.

Owston, R., Lupshenyuk, D. \& Wideman, H. (2011) Lecture Capture in Large Undergraduate Classes: Student Perceptions and Academic Performance. The Internet and Higher Education, 14(4), 262-268

Pratt, D. D. (1992) Conceptions of Teaching. Adult Education Quarterly, 42(4), 203220.

Price, D., \& Almpanis, T. (2015) Student and Staff Perceptions on the Impact of Lecture Capture. ICICTE 2015 Proceedings, 215-225

Prosser, M., Trigwell, K. and Taylor, P. (1994) A Phenomenographic Study of Academics' Conceptions of Science Learning and Teaching. Learning and Instruction, 4(3), 217-231

Pursel, B, and Fang, H. N. (2012) Lecture Capture: Current Research and Future Directions. Schreyer Institute for Teaching Excellence, Pennsylvania State University

Rios-Amaya, J. Secker, J. \& Morrison, C. Lecture Recording in Higher Education: Risky business or evolving open practice. Available from: http://eprints.Ise.ac.uk (accessed 22 October 2017).

Samuelowicz, K. \& Bain, J. D. (1992) Conceptions of Teaching Held by Academic Teachers. Higher Education, 24(1), 93-111

Schon, D. A. (1987) Educating the reflective practitioner: Toward a new design for teaching and learning in the professions (San Francisco, Jossey-Bass)

Terry, N., Marcy, A., Clarke, R. \& Sanders G. (2015) The Impact of Lecture Capture on Student Performance in Business Courses. Journal of College Teaching \& Learning (TLC), 12(1), 65-74

Tight, M. (2012) Researching Higher Education, (McGraw-Hill Education, UK)

Toppin, I. (2011). Video lecture capture (VLC) system: A comparison of student and faculty perceptions. Education and Information Technologies 16, 383-393.

Traphagan, T., Kucsera, J. V. \& Kishi, K., (2009) Impact of Class Lecture Webcasting on Attendance and Learning. Educational Technology Research \& Development, 58(1), 19-37 
UCISA (2016) 2016 Survey of Technology Enhanced Learning for higher education in the UK. https://www.ucisa.ac.uk/tel [accessed 18 October 2017].

Van Manen, M. (1991) The tact of teaching (Albany, NY, Suny Press)

Williams, A., Birch, E. \& Hancock, P. (2012) The Impact of Online Lecture Recordings on Student Performance. Australasian Journal of Educational Technology, 28(2), 199-213

Whitley-Grassi, N. \& Baizer, J. S. (2010) Video Lecture Capture in Physiology Courses: Student Attendance, Video Viewing and Correlations to Course Performance. International Journal of Instructional Technology and Distance Learning, 7(10), 31-38

Witthaus, G \& Robinson, C. (2015) Lecture Capture Literature Review: A review of the literature from 2012 to 2015. Centre for Academic Practice, (Leicestershire: Loughborough University)

Witton, G. (2016) The value of capture: Taking an alternative approach to using lecture capture technologies for increased impact on student learning and engagement. British Journal of Educational Technology, 48 (4), 1010-1019. 